\title{
Official controls on carry-over of antibiotics in feed: A useful tool to contain the development of antibiotic resistance
}

\author{
Rosa Avolio $^{1 *}$, Sabina Pederiva ${ }^{1}$, Sara Morello ${ }^{1}$, Maria I Crescio ${ }^{1}$, Giuseppe Ru ${ }^{1}$, Fabrizio Grifoni ${ }^{2}$, Maria C Abete ${ }^{1}$ and Daniela Marchis ${ }^{1}$ \\ ${ }^{1}$ Istituto Zooprofilattico Sperimentale del Piemonte, Liguria e Valle d'Aosta. Via Bologna 148, Turin, 10154, Italy \\ ${ }^{2}$ ASL TO3, Veterinary Service TO3, Via Poirino, 9, Pinerolo, (TO), 10064, Italy
}

\begin{abstract}
Medicated feeds are widely used to treat bacterial infection in poultry, pig and aquaculture. During feed production process, carry-over can occur as an unintentional but unavoidable presence of traces of active substances in a feed batch to the next ones. Sharing information overall among different countries is a crucial step in order to contain development of microbial drug resistance, which represent a key concern and a research priority. So far, European Union (EU) rules do not provide any carry-over action limit for antibiotics in feed, whereas since 2015 the Italian Competent Authorities established action limits based on the 'as low as reasonably achievable' (ALARA) principles. This study aimed to investigate antibiotics at carry-over level as part of the official feeding-stuffs controls carried out between 2017 and 2020 in North-West of Italy (Piedmont, Liguria and Aosta Valley). Analyses were carried out applying accredited in-house methods, performed with high-performance liquid chromatography with diode-array detector (HPLC-DAD), with fluorescence detector (HPLC-FLD) and with electrospray tandem mass spectrometry (HPLC-MS/MS), to detect different classes of antibiotics. Collected data highlight a decreasing trend of non-compliant samples along the examined period. The most identified compound were tetracyclines which are widely used because of their cost-effective activity. Indeed, swine are confirmed to be the most commonly treated species. Systematic measurement of antimicrobial, at carry-over level in feed is an effective tool to contain the development of antimicrobial resistance. Focused and effective steps on the optimisation antimicrobials use may help to improve feed safety and enhance animal and human welfare.
\end{abstract}

\section{Introduction}

Approved veterinary drugs (i.e., tetracyclines, penicillins, sulfonamides) are widely used in poultry, pig and aquaculture feed to treat bacterial infections $[1,2]$. Within the EU the use of medicated feeds requires a prescription by authorised professionals, according to the label directions [3]. In Italy veterinarians only are authorized to prescribe antimicrobial treatments through different routes of administration, medicated feed included.

Medicated feeds containing different active ingredients may be processed in the same product plant, so medicated and non-medicated feeding stuffs can be actually produced using a single production line, provided they are cleaned beforehand, in accordance with a documented procedure authorized by the Competent Authority (CA). Nevertheless, traces of active substances or drugs in one batch could eventually persist and transferred in the next feed batches. Carry-over is an unintentional but unavoidable occurrence, which may happen even when identification and control of Hazard Analysis and Critical Control Points (HACCP), and Good Manufactory Practices (GMPs) are followed.

Drug residues in feed, basically antibiotics, may have a deep impact on animal health and on a possible involvement in the development of AMR [4], and it can be expected to occur at each step from primary production, processing, manufacture, storage and feed transport.

Undesirable risks related to this problem are due to possible adverse health effects in target and non-target animals, and therefore in food $[2,5]$. The use of antimicrobials through animal feed could determine an increased incidence and selection of bacteria resistant to these active compounds [6]. The aftermath of carry-over is an unintentional administration of underdosed antibiotics through feed, which may act as a potential contributing factor to AMR occurrence.

Guidelines for the prudent use of antimicrobials in veterinary medicine [7] claim to avoid systematic use of antibiotics, minimising the development of AMR and limiting their use to those situations where they are indeed required.

In 2019 FAO (FAO Animal Production and Health Report No. 132019) [8] pointed out the need of reducing and preventing food safety hazards through a focused monitoring activity, which should be also be carried out on feed.

The scientific risk assessment performed by the European Food Safety Authority (EFSA), the application of GMPs and the ALARA principle have been considered by government regulatory agencies [9] (Reg. EU, 2019/4).

Currently, the EU rules do not provide any carry-over action limit for antibiotics in feed, whereas in Italy, since 2015 and based on the

${ }^{\star}$ Correspondence to: Rosa Avolio, Istituto Zooprofilattico Sperimentale del Piemonte, Liguria e Valle d'Aosta. Via Bologna 148, Turin, 10154, Italy, Tel. 01190224233; Email address: rosa.avolio@izsto.it

Key words: monitoring plan; high-performance liquid chromatography; tetracyclines; swine; antibiotics analyses

Received: April 13, 2021; Accepted: April 20, 2021; Published: April 27, 2021 
ALARA principles, action limits have been established $(0.5 \mathrm{mg} / \mathrm{kg}$ amoxicillin and ampicillin and $1.0 \mathrm{mg} / \mathrm{kg}$ all the other antimicrobials). Moreover, a number of national meetings have been organised in order to improve both the harmonisation of analytical procedures and promoting a consistent approach of feed business operators on this specific issue.

Finally, since 2015 ICA have implemented a National Animal Feed Plan (PNAA) and have enhanced controls on carry-over level detection of additives and antimicrobials in feed. The aim of this study was to provide information on carry-over occurrence in feeding stuffs in our competent territory. Monitoring data collection help to identify factors which may increase the prevalence of the overall antibiotic resistance.

\section{Materials and methods}

\section{Data collection and samples selection}

Examined data in this study were recorded as part of the official feeding stuffs controls carried out between 2017 and 2020 in the north-west area of Italy (Piedmont, Liguria and). Samples were collected in farms and in feed mills by Local Competent Authorities (LCA), according to Regulation (EC) 691/2013 [10]. In order to gather representative specimens, each lot of feeding-stuffs was repeatedly sampled, taking incremental samples in different single points of the batch and ensuring homogeneity of sampling.

Globally, 785 feed samples were collected and processed: 175 in 2017, 215 in 2018, 229 in 2019 and 166 in 2020. Of these, 61\% were complete feed, $18 \%$ complementary feed, $15 \%$ farm feed and $6 \%$ raw materials (i.e. terrestrial animal proteins or fish meal). 59\% of collected samples was taken from farm and $41 \%$ in feed mills, the most involved species was porcine (42\%) (Table $1 \mathrm{a}$ and $1 \mathrm{~b})$.

\section{Analytical methods}

The official samples were analysed for determination of the following antimicrobials: penicillins, quinolones, colistin, amphenicol, lincomycin, macrolides, valnemulin, nicarbazin, sulfonamides, tetracycline, thiamphenicol and tiamulin. Analyses were carried out applying accredited in-house methods, according to UNI CEI EN ISO/
IEC 17025. Analytical methods and Limits of Quantification (LOQ) are reported in the Table 2 .

\section{Results}

Out of the 785 collected samples, 24 were non-compliant to at least one active principle. Of these $75 \%$ were complete feed, $16 \%$ farm feed, while $9 \%$ were complementary feed; the highest number of noncompliant samples was found in $2017(\mathrm{n}=19)$ and porcine feed $(\mathrm{n}=10)$ appeared to be the most involved category, followed by rabbit $(n=5)$ and bovine feeding-stuff $(n=4)$, while in $2018(n=3)$ and $2019(n=2)$ all non-compliant samples were porcine feed. Indeed, feed mills irregular samples were higher $(n=14)$ than those found in farm $(n=10)$ (Table $1 b)$.

As reported in Table 3, tetracyclines appeared to be the more frequently detected antimicrobials during the whole period, while penicillins were found in 2017 only, and other analytes such as nicarbazin, tiamulin, thiamphenicol, sulfadiazine were found just once (Samples ID: 2-CF, 21-CF, 1-CF, 9- CF). Number of non-compliant samples significantly decreased from 2017 to 2019, while no cases were registered in 2020 .

In 2019 non-compliant samples were registered for tetracyclines only (samples ID: 23-CF e 24-CF). Lincomycin was detected twice, in 2017 and in 2018 respectively (Samples ID: 3-COMF, 20-CF).

Overall, $54 \%$ of the 24 irregular samples showed to contain tetracyclines (10/19 in 2017, 1/3 in 2018, 2/2 in 2019 respectively). Two porcine complete feeds were found to contain both doxycycline and oxytetracycline (14-CF), or doxycycline and chlortetracycline (23-CF).

The amoxicillin concentration in porcine feed in 2017 ranged from 1.3 to $12 \mathrm{mg} / \mathrm{kg}$, while the only ampicillin non-compliant sample was found to contain $7.8 \mathrm{mg} / \mathrm{kg}$ (Sample ID 8-CF).

\section{Discussion}

This retrospective study highlights that carry-over occurrence of tetracyclines could be rather common in pigs supply chain. However, over the study the percentage of non-compliant samples significantly

Table 1. Sample description (2017-2020): (a) Collected samples, (b) Non-compliant samples

\begin{tabular}{|c|c|c|c|c|c|c|c|c|c|c|}
\hline & \multicolumn{5}{|c|}{ (a) Collected samples } & \multicolumn{5}{|c|}{ (b) Non-compliant samples } \\
\hline & 2017 & 2018 & 2019 & 2020 & Total & 2017 & 2018 & 2019 & 2020 & Total \\
\hline \multicolumn{11}{|l|}{ Sample description } \\
\hline Complete feed & 110 & 128 & 136 & 106 & $480(61 \%)$ & 14 & 3 & 2 & 0 & $19(75 \%)$ \\
\hline Complementary feed & 29 & 30 & 38 & 26 & $123(18 \%)$ & 1 & 0 & 0 & 0 & $1(9 \%)$ \\
\hline Farm feed & 35 & 29 & 23 & 16 & $103(15 \%)$ & 4 & 0 & 0 & 0 & $4(16 \%)$ \\
\hline Raw materials & 1 & 28 & 32 & 18 & $79(6 \%)$ & 0 & 0 & 0 & 0 & 0 \\
\hline Total & 175 & 215 & 229 & 166 & $785(100 \%)$ & 19 & 3 & 2 & 0 & $24(100 \%)$ \\
\hline \multicolumn{11}{|l|}{ Sampling site } \\
\hline Farm & 111 & 129 & 131 & 96 & $467(59 \%)$ & 7 & 2 & 1 & 0 & $10(71 \%)$ \\
\hline Feed mills & 65 & 85 & 98 & 70 & $318(41 \%)$ & 12 & 1 & 1 & 0 & $14(58 \%)$ \\
\hline Total & 176 & 214 & 229 & 166 & $785(100 \%)$ & 19 & 3 & 2 & 0 & $24(100 \%)$ \\
\hline \multicolumn{11}{|l|}{ Involved species } \\
\hline Porcine & 88 & 92 & 86 & 62 & $328(42 \%)$ & 10 & 3 & 2 & 0 & $15(62 \%)$ \\
\hline Poultry & 24 & 36 & 41 & 33 & $134(17 \%)$ & 0 & 0 & 0 & 0 & 0 \\
\hline Rabbit & 25 & 25 & 22 & 17 & $89(11 \%)$ & 5 & 0 & 0 & 0 & $5(21 \%)$ \\
\hline Bovine & 23 & 19 & 25 & 17 & $84(11 \%)$ & 4 & 0 & 0 & 0 & $4(17 \%)$ \\
\hline Pets & 0 & 16 & 28 & 13 & $57(7 \%)$ & 0 & 0 & 0 & 0 & 0 \\
\hline Other species & 15 & 27 & 27 & 24 & $93(12 \%)$ & 0 & 0 & 0 & 0 & 0 \\
\hline Total & 175 & 215 & 229 & 166 & $785(100 \%)$ & 19 & 3 & 2 & 0 & $24(100 \%)$ \\
\hline
\end{tabular}


Table 2. Analytical methods and LOQs

\begin{tabular}{|c|c|c|}
\hline Compounds & LOQs $(\mathbf{m g} / \mathbf{k g})$ & Methods \\
\hline Penicillins & 0.50 & LC-MS/MS \\
\hline Tetracycline & 0.50 & HPLC-DAD \\
\hline Thiamphenicol & 0.50 & LC-MS/MS \\
\hline Lincomycin & 0.25 & LC/MS \\
\hline Tiamulin & 0.50 & LC-MS \\
\hline Sulfonamides & 1.0 & HPLC-DAD \\
\hline Quinolones & 0.025 & HPLC-FLD \\
\hline Valnemulin & 0.010 & LC/MS \\
\hline Colistin & 0.10 & LC-MS/MS \\
\hline Amphenicol & 0.10 & LC-MS/MS \\
\hline Macrolides & 0.10 & LC-MS/MS \\
\hline
\end{tabular}

Table 3. Non-compliant samples

\begin{tabular}{|c|c|c|c|c|c|}
\hline Year & Sample ID & Species & $\begin{array}{l}\text { Classes Of } \\
\text { Antibiotics }\end{array}$ & Compound & $\begin{array}{c}\text { Level } \pm \text { SD } \\
(\mathrm{mg} / \mathbf{k g})\end{array}$ \\
\hline \multirow{20}{*}{ 今) } & $1-(\mathrm{CF})^{1}$ & PORCINE & Amphenicol & Thiamphenicol & $2.4 \pm 0.40$ \\
\hline & $2-(\mathrm{CF})$ & POULTRY & Coccidiostat & Nicarbazin & $14 \pm 0.40$ \\
\hline & $3-(\mathrm{COMF})^{2}$ & BOVINE & Lincosamides & Lincomycin & $1.5 \pm 0.31$ \\
\hline & 4-(CF) & PORCINE & Penicillins & Amoxicillin & $1.4 \pm 0.40$ \\
\hline & $5-(\mathrm{CF})$ & PORCINE & Penicillins & Amoxicillin & $1.3 \pm 0.40$ \\
\hline & $6-(\mathrm{CF})$ & PORCINE & Penicillins & Amoxicillin & $12 \pm 3.3$ \\
\hline & 7-(FF) ${ }^{3}$ & PORCINE & Penicillins & Amoxicillin & $2.0 \pm 0.60$ \\
\hline & $8-(\mathrm{CF})$ & PORCINE & Penicillins & Ampicillin & $7.8 \pm 2.0$ \\
\hline & $9-(\mathrm{CF})$ & BOVINE & Sulfonamides & Sulfadiazine & $3.2 \pm 0.25$ \\
\hline & $10-(\mathrm{CF})$ & PORCINE & Tetracyclines & Chlortetracycline & $1.8 \pm 0.60$ \\
\hline & 11-(FF) & PORCINE & Tetracyclines & Chlortetracycline & $4.3 \pm 0.52$ \\
\hline & 12-(FF) & RABBIT & Tetracyclines & Doxycycline & $6.3 \pm 2.0$ \\
\hline & 13-(FF) & PORCINE & Tetracyclines & Doxycycline & $1.3 \pm 0.10$ \\
\hline & \multirow{2}{*}{$14-(\mathrm{CF})$} & BOVINE & Tetracyclines & Doxycycline & $10 \pm 2.0$ \\
\hline & & BOVINE & Tetracyclines & Oxytetracycline & $2.1 \pm 0.70$ \\
\hline & 15-(COMF) & BOVINE & Tetracyclines & Oxytetracycline & $11 \pm 1.5$ \\
\hline & 16-(CF) & BOVINE & Tetracyclines & Oxytetracycline & $6.3 \pm 0.87$ \\
\hline & $17-(\mathrm{CF})$ & RABBIT & Tetracyclines & Oxytetracycline & $2.6 \pm 0.36$ \\
\hline & $18-(\mathrm{CF})$ & RABBIT & Tetracyclines & Oxytetracycline & $5.6 \pm 0.78$ \\
\hline & 19-(CF) & RABBIT & Tetracyclines & Oxytetracycline & $6.2 \pm 0.86$ \\
\hline \multirow{3}{*}{$\stackrel{\infty}{\stackrel{\sim}{二}}$} & 20-(CF) & PORCINE & Lincosamides & Lincomycin & $5.6 \pm 0.91$ \\
\hline & 21-(CF) & PORCINE & Pleuromutilin & Tiamulin & $44 \pm 7.5$ \\
\hline & $22-(\mathrm{CF})$ & PORCINE & Tetracyclines & Doxycycline & $83 \pm 6.6$ \\
\hline \multirow{3}{*}{ ิㅡㄹ } & \multirow[t]{2}{*}{$23-(\mathrm{CF})$} & PORCINE & Tetracyclines & Chlortetracycline & $0.61 \pm 0.17$ \\
\hline & & PORCINE & Tetracyclines & Doxycycline & $2.8 \pm 0.39$ \\
\hline & 24-(CF) & PORCINE & Tetracyclines & Oxytetracycline & $2.8 \pm 0.39$ \\
\hline
\end{tabular}

decreased, and tetracyclines appeared to be the sole antimicrobial class identified in 2019, with no irregular samples detected in 2020.

Many countries have banned antibiotic use as growth promoters, but it has been demonstrated that the use of antibiotics for infection prevention and prophylactic purpose is still rather common in pig production to prevent production loss [11].

In porcine feed penicillins and tetracyclines are the most commonly used antibiotics, due to their cost-effective activity compared to other antibiotics [12]. Their use is often linked to poor plant efficiency and deficient hygiene and welfare conditions, which could result a decreased production and lead to a higher need of antimicrobial treatments $[13,14]$. The decline of positive samples collected over the years suggests that existing monitoring plans are effective to control carry-over occurrence. Besides, the application of quality management schemes $[15,16]$, more awareness of feed business operators and improved animal welfare conditions appear to contribute positively to a better application of GMP.

\section{Conclusion}

The results of our study could be a useful point of view to enhance critical points in feed supply-chain, to ensure a higher level of feed safety and protection of public health and contribute to improve the procedures requirements to minimize carry-over in feed. Our results have been useful shape the ongoing Italian plan (PNAA 2021-2023) for feed monitoring and sampling and might contribute to feed data which could be take into account to improve aware use of antibiotics in farm animals.

\section{References}

1. Barbosa Da Silva A, Back M, Daguer H, Palmeira M, De Sá Ploêncio LA, et al. (2019) Carry-over and contamination of veterinary drugs in feed production lines for poultry and pigs. Food Addit Contam 36: 5: 740-751. [Crossref]

2. Mantovani A, Maranghi F, Purificato I, Macri A (2006) Assessment of feed additives and contaminants: an essential component of food safety. Ann Ist Super Sanita 42: 427-432. [Crossref]

3. European Commission Directorate General for Health and Consumers, 2010 Evaluation of the EU Legislative Framework in the Field of Medicated Feed. Brussels.

4. Feiyang M, Shixin X, Zhaoxin T, Zekun L, Lu Z (2020) Use of antimicrobials in food animals and impact of transmission of antimicrobial resistance on humans. Biosafety and Health 3: 32-38.

5. Bampidis V, Bastos M, Christensen H, Dusemund B, Kouba M, et al. (2019) EFSA FEEDAP Panel (EFSA Panel on Additives and Products or Substances used in Anima Feed), Guidance on the assessment of the safety of feed additives for the environment EFSA J 17: 5648-5678.

6. EN, 2019, Special Report $\mathrm{N}^{\circ} 21$ : Addressing antimicrobial resistance: Progress in the animal sector, but this health threat remains a challenge for the EU.

7. EN (2015) Guidelines for the prudent use of antimicrobials in veterinary medicine Official Journal of the European Union, 2015/C 299/04.

8. FAO and WHO. 2019. Carry-over in feed and transfer from feed to food of unavoidable and unintended residues of approved veterinary drugs. Report of the Joint FAO/WHO expert meeting - 8-10 January 2019, FAO Headquarters, Rome, Italy. FAO Animal Production and Health Report No. 13. Rome, Italy.

9. Commission Regulation (EU) No. 2019/4, 11/12/2018, on the manufacture, placing on the market and use of medicated feed, amending Regulation (EC) No 183/2005 of the European Parliament and of the Council and repealing Council Directive 90/167/EEC.

10. Commision Regulation (EU) No. 2013/691, 19/07/2013, amending Regulation (EC) No 152/2009 as regards methods of sampling and analysis.

11. Lekagul A, Tangcharoensathien V, Yeung S (2018) The use of antimicrobials in global pig production: A systematic review of methods for quantification. Prev Vet Med 160: 85-98. [Crossref]

12. Lekagul A, Tangcharoensathien V, Yeunga S (2019) Patterns of antibiotic use in global pig production: A systematic review. Veterinary and Animal Science 7: 100058.

13. Aarestrup FM, Jensen VF, Emborg HD, Jacobsen E, Wegener HC (2010) Changes in the use of antimicrobials and the effects on productivity of swine farms in Denmark. Am $J$ Vet Res 71:726-733. [Crossref]

14. Heo JM, Opapeju FO, Pluske JR, Kim JC, Hampson DJ, et al. (2013) Gastrointestina health and function in weaned pigs: a review of feeding strategies to control postweaning diarrhoea without using in-feed antimicrobial compounds. J Anim Physiol Anim Nutr (Berl) 97: 207-237. [Crossref]

15. FAO (2004) The Codex code of practice on good animal feeding, section 6, CAC/RCP 54-2004.

16. WHO (2017) Guidelines on use of medically important antimicrobials in foodproducing animals. Geneva: World Health Organization; Licence: CC BY-NC-SA 3.0 IGO.

Copyright: (C2021 Avolio R. This is an open-access article distributed under the terms of the Creative Commons Attribution License, which permits unrestricted use, distribution, and reproduction in any medium, provided the original author and source are credited. 